\title{
4 Design Themes for Skateboarding
}

\author{
Sebastiaan Pijnappel \\ Exertion Games Lab \\ RMIT University \\ Melbourne, Australia \\ sebastiaan@exertiongameslab.org
}

\author{
Florian 'Floyd' Mueller \\ Exertion Games Lab \\ RMIT University \\ Melbourne, Australia \\ floyd@exertiongameslab.org
}

\begin{abstract}
Interactive technology can support exertion activities, with many examples focusing on improving athletic performance. We see an opportunity for technology to also support extreme sports such as skateboarding, which often focus primarily on the experience of doing tricks rather than on athletic performance. However, there is little knowledge on how to design for such experiences. In response, we designed 12 basic skateboarding prototypes inspired by skateboarding theory. Using an autoethnographical approach, we skated with each of these and reflected on our experiences in order to derive four design themes : location of feedback in relation to the skater's body, timing of feedback in relation to peaks in emotions after attempts, aspects of the trick emphasized by feedback, and aesthetic fittingness of feedback. We hope our work will guide designers of interactive systems for skateboarding and extreme sports in general, and will therefore further our understanding of how to design for the active human body.
\end{abstract}

\section{Author Keywords}

Skateboarding; experience of attempting tricks; autoethnography; extreme sports; exertion.

\section{ACM Classification Keywords}

H.5.2. [Information Interfaces and Presentation]: User Interfaces: Miscellaneous.

\section{General Terms}

Design; Human Factors.

\section{INTRODUCTION}

We are interested in interactive technology for sports, as several works indicate the potential of interactive technology to support the exertion experience [4]. We note that most of the existing works focus on honing athletic performance and fitness parameters. For example, systems exist that aim to improve rowers' speed [1]. In contrast, we find that not all sports activities are oriented

Permission to make digital or hard copies of all or part of this work for personal or classroom use is granted without fee provided that copies are not made or distributed for profit or commercial advantage and that copies bear this notice and the full citation on the first page. To copy otherwise, or republish, to post on servers or to redistribute to lists, requires prior specific permission and/or a fee.

CHI 2013, April 27-May 2, 2013, Paris, France.

Copyright (C) 2013 ACM 978-1-4503-1899-0/13/04...\$15.00. primarily towards athletic performance, neither are all sports participants. Many extreme sports, such as skateboarding, focus strongly on the experience of doing tricks. This is often of a subjective nature, as opposed to the objective quality of athletic performance goals. We believe that interactive technology can also contribute to exertion activities that focus on the experience of doing tricks, yet there is little knowledge about how to design for such experiences. With this paper we aim to contribute to this knowledge.

We focus on skateboarding as an example of a extreme sports that focuses on attempting tricks. Other examples are BMX, snowboarding, freestyle motocross and parkour. Skateboarding involves participants trying to perform tricks with their board, such as flipping it 360 degrees underneath their feet (kick-flip), or sliding it over a handrail (board slide). We note that the process of repetitively trying to perform a certain trick and ultimately landing it can be a powerful subjective experience. It comprises emotions such as the excitement and satisfaction that comes with progressing at and finally mastering a trick [7]. This experience is often the primary motivation for participants to engage in skateboarding [7].

INTERACTIVE TECHNOLOGY AND SKATEBOARDING A few prior works have aimed to support the skateboarding experience. Two interactive installations, built for public events particularly inspired us. The Skate Sonic system [9] translates movements of skaters into a "sonic landscape". Similarly, the Tron Legacy Ramp is a skateboarding ramp augmented with projections that show scores indicating how long skaters were in the air during jumps [10]. Both systems support the skateboarding experience in a way that leaves the original skateboarding movements unaffected, yet they provide feedback relating to these movements, presented in different sensory modalities. We felt inspired by these approaches and hence decided to also focus on supporting the skateboarding experience with feedback, while celebrating the core activity: attempting tricks.

In order to better understand this core activity we look at the work by Seifert and Hedderson [7], who tell us that the emotions key to the experience of attempting mostly tricks occur mostly right after the attempt, rather than before or during. We therefore believe that in order to support the experience of attempting tricks, one way forward is to focus on supporting these emotions. 
Tholander and Johansson [11] tell us that the interaction with the skateboard and the environment provides skaters with rich inherent feedback regarding their actions, for example feeling the texture of an obstacle through the board or hearing the board land on the floor. The authors argue that this inherent feedback is key to the skaters' perception of their tricks, which in turn is key to the skateboarding experience [11]. The paper identifies three forms of feedback to be important in this respect: visual, aural and haptic [11]. In response, we see an opportunity for technology to provide feedback that can be perceived after the execution of tricks across these three modalities.

Countless hours of amateur skateboarding videos on YouTube suggest that skateboarders value the use of technology to capture, relive and share their experiences. However, capturing and sharing video is time consuming and typically takes place after the skateboarding session. Although virtual, computer games such as Tony Hawk's Pro Skater show interesting examples of more immediate feedback to support the skating experience, such as instant replay or color tagging of obstacles. Our work draws on the idea of immediate feedback and the use of technology to review and relive parts of the skateboarding experience.

In sum, skateboarding theory and existing systems suggest that there is an opportunity for interactive technology to benefit the skateboarding experience. However, there is little systematic understanding of how to design interactive technology for skateboarding. Our autoethnography work presented in the next section makes a start in building this understanding.

\section{PROTOTYPES FOR SKATEBOARDING}

We designed 12 basic prototypes of interactive feedback systems to support the experience of attempting skateboarding tricks (Table 1), focusing on visual, aural and haptic feedback as inspired by skateboarding theory [7][11]. We created 3 to 5 prototypes for each modality, as we felt this was a suitable number to cover a range of feedback forms. We use an autoethnographic approach [3] to study the experience with these prototypes, as the main investigator is an avid skater with 5 years of experience.

The main investigator (referred to as 'I' from now on) skated with each of the prototypes, after which we discussed recurring qualities and limitations. The results are four design themes aimed to support designers of future interactive systems for skateboarding.

\section{Autoethnographic Approach}

Autoethnography is "a form of autobiographical personal narrative that explores the writer's experience of life" [3], in our case the first author's experience of skateboarding. Autoethnography has recently gained traction in HCI, and we opted for it for four reasons: firstly, autoethnography can allow for the fullest account of an experience, as no information is lost in communication or interpretation

\begin{tabular}{|l|l|}
\hline No. & Prototype functionality \\
\hline 1 & $\begin{array}{l}\text { Projection that shows recorded video of trick } \\
\text { attempt, displayed in real size }\end{array}$ \\
\hline 2 & $\begin{array}{l}\text { Projected image that shows tracked trajectory of } \\
\text { board as single thin line, displayed in real size }\end{array}$ \\
\hline 3 & $\begin{array}{l}\text { Projected image that shows tracked trajectory of } \\
\text { front and rear of board as 2 separate lines, } \\
\text { displayed in real size }\end{array}$ \\
\hline 4 & $\begin{array}{l}\text { Recorded audio of attempt is replayed at 0.5x } \\
\text { speed }\end{array}$ \\
\hline 5 & $\begin{array}{l}\text { Attempting trick starts prerecorded audio, } \\
\text { playback speed is changed live according to } \\
\text { movement of skater, and restores to normal } \\
\text { upon successfully landing the trick }\end{array}$ \\
\hline 6 & $\begin{array}{l}\text { Same as no. 5, but energetic song is started upon } \\
\text { successfully landing the trick }\end{array}$ \\
\hline 7 & $\begin{array}{l}\text { Same as no. 6, but song experiences skipping } \\
\text { until successfully landing the trick }\end{array}$ \\
\hline 8 & $\begin{array}{l}\text { Coarseness of floor texture is changed (by } \\
\text { moving textured tarpaulin) in relation to quality } \\
\text { of trick execution }\end{array}$ \\
\hline 9 & $\begin{array}{l}\text { Skateboard accelerates upon successful landing } \\
\text { of trick (using motorized skateboard) }\end{array}$ \\
\hline 10 & $\begin{array}{l}\text { Strings attached to skater are jerked erratically } \\
\text { or subtly after trick, depending on trick quality }\end{array}$ \\
\hline 11 & $\begin{array}{l}\text { Strings attached to skater are jerked after trick } \\
\text { in rhythm of movements of skater during trick }\end{array}$ \\
\hline 12 & $\begin{array}{l}\text { Floor surface is vibrated (with a low-frequency } \\
\text { audio transducer) in rhythm of movements of } \\
\text { skater during trick }\end{array}$ \\
\hline & able $1:$ Overview of protyped deas \\
\hline
\end{tabular}

Table 1: Overview of prototyped ideas

between participant and researcher [2]. It thus seems to be a valuable tool for inquiry into the skateboarding experience. Secondly, autoethnography allows for rapid design iterations [5], enabling us to explore a wide scope of radically different prototypes, as it capitalizes on the designer's tacit knowledge (one of the key benefits of reflective practice according to Schön [6]) to quickly reflect on and evolve prototypes. Thirdly, research suggests that bodily experiences such as skateboarding are best understood by going through them oneself [3]. Finally, we wanted to retain the 'extreme' quality of skateboarding as being an extreme sport, and came up with prototypes that involve activities that are potentially dangerous for participants, for example pulling strings attached to the skater's legs while skateboarding. Autoethnography allowed us to try these ideas out without compromising participants' safety (except our own). 

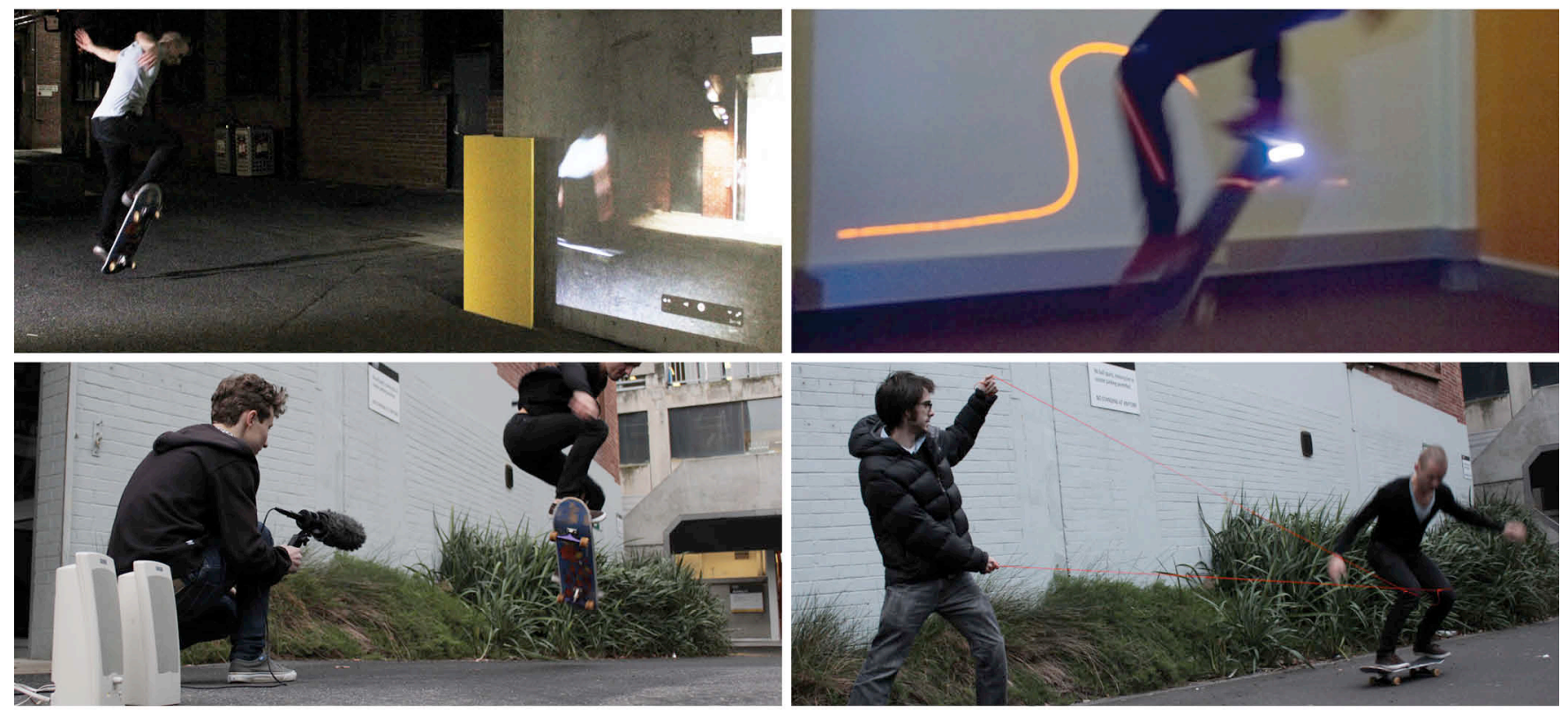

Figure 1: Skating with instant video playback, with images of trajectory of board, with instant audio playback, and with strings pulled to provide haptic feedback.

\section{Skateboarding with the 12 Prototypes}

I skateboarded for at least 20 minutes with each prototype to allow ample time for the key emotions to occur (they occur right after tricks, rather than after the skateboarding session [7]). Sessions were videotaped, and I took notes during breaks. Each session concluded with personal reflections, followed by discussions with other skaters and researchers supported by video I took.

\section{DESIGN THEMES FOR SKATEBOARDING}

Our work resulted in 4 design themes.

\section{Location of Feedback in Relation to the Skater's Body My Experiences}

I noticed that the visual feedback systems (no.1-3) required me to turn around and focus on particular locations in space to see them properly. This conflicted with my urge to celebrate successful attempts by doing a few little jumps with my board. Auditory information on the other hand "filled" the space and could more effortlessly be perceived wherever and during whatever movement (no.4-7). This allowed me to physically express myself with fewer constraints. For example, I raised my arms when landing a trick as part of my expression of excitement, while the playback speed of an audio file going from sluggish to fast at that moment complemented this nicely.

\section{Resulting Theme}

We encourage designers to consider where in the space feedback is available in relation the skater's body, as this can have an effect on the skater's ability to physically express emotions while still perceiving the feedback.

Skateboarding involves movement of the body not only during, but also after tricks. This movement contributes to the self-expression of emotions such as excitement. Previous research highlights the importance of these performative actions as part of movement-based interactions [4]. Here we extend this work by arguing that feedback needs to consider this performative action in relation to the space the after-trick movement occupies.

\section{Timing of Feedback in Relation to Peaks in Emotions After Attempts \\ My Experiences}

I found myself reading into nuances of projected images (no.2,3) after successful attempts, appreciating how well I did at certain aspects of a trick, which in turn affected my experience of pride. Rather than only affecting emotions already arising immediately after an attempt, these emotions of pride made for a new peak in emotions several seconds later. Feedback that did not persist over time (no.1,4,8-12) did not allow for this to occur.

After failed attempts I found that my attention moved on to the next attempt almost right away. In this case only feedback that was presented immediately after attempts (no.5-8) managed to affect my emotions. For example, a brief moment of frustration was intensified by the unpleasant jolting caused by the coarse surface texture felt immediately after I had landed on the ground (no.8).

\section{Resulting Theme}

We encourage designers to consider the point in time at which feedback is presented to the user in relation to peaks in emotions that occur after attempts. Whether feedback is presented immediately or several seconds after attempts, and whether or not it persists over time, affects whether it can enhance or dampen these emotions, create new peaks in emotions, or if it will fail to have an 
effect. Previous research mentions the importance of peaks in emotions during skateboarding [7]. Here we add that feedback should consider the timing of these peaks.

\section{Aspects of the Trick Emphasized by Feedback My Experiences}

I noticed that forms of feedback that emphasized movements of the board were able to instill or even enhance a sense of achievement, as the fluency and shape of the trajectory of the board through the air was what I cared a lot about in my tricks. The still images for example (which only showed the board's trajectory) did well in this respect, often leaving me with a feeling of "yes, I did that really well!" (no.2,3). In contrast, video showed body, board and context, but emphasized neither of these aspects (no.1). Consequently, it lacked the ability to boost pride over how I managed to move my board through the air. Recorded audio emphasized the take off and landing, but seemed to lack impact on my experience, as these aspects simply were not as crucial to how I felt about the attempt as other parts of the trick (no.4).

\section{Resulting Theme}

We encourage designers to consider what aspects of a trick feedback can bring to the skater's attention, as different aspects have different levels of significance to the experience. This theme thus affects how feedback can enhance specific feelings of achievement integral to the experience of attempting tricks.

\section{Aesthetic Fittingness of Feedback My Experiences}

I noticed the aesthetic appeal of feedback affected the potential to foster my feelings of pride over tricks done. Forms of feedback with a strong aesthetic appeal (e.g. projected images, no.2,3) had a more profound effect on these feelings than ones with limited aesthetic appeal (no.4,7,10-12). In my experience, the strong aesthetic appeal of the feedback did justice to the aesthetic appeal of the trick I had just performed. It appeared to affirm my skill and reward my effort with an aesthetically pleasing "prize".

\section{Resulting Theme}

We encourage designers to think about the aesthetic quality of the feedback they present, as aesthetic qualities that are fitting to the movements performed seem to positively contribute to the experience of pride over tricks. This could for example mean that a fluent motion should result in a fluent looking visualization, while choppily executed movement should result in jagged visualizations.

We want to highlight that feedback aesthetics is not just the domain of visual feedback, but of haptic and aural as well. For instance, a surface texture that feels unpleasant (no.8) can be said to have an unappealing aesthetic, and could thus be considered in feedback on poorly executed tricks.

\section{FUTURE WORK}

Skateboarding is often done in groups, and as Sheridan [8] notes, audiences play a strong role in exertion activities. Hence we recommend to other researchers to extend our work by looking at the performative aspect of skateboarding, answering questions like: can interactive technology enhance the audience's experience, or the skateboarder's experience of performing for an audience?

\section{CONCLUSION}

We identified 4 design themes for interactive technologies to support the experience of attempting tricks in skateboarding. We thereby expand the body of knowledge on how to design interactive technologies for exertion activities by providing insights into the support of extreme, trick-focused sports. By doing so, we aim to point interaction designers at the exciting opportunities to support the active human body beyond merely enhancing athletic performance. Furthermore, we hope our work helps offer skaters a more engaging skateboarding experience, and entices more people to skate. This could ultimately allow more people to profit from the many benefits physical activity can offer.

\section{REFERENCES}

1. Baca, a. and Kornfeind, P. Rapid Feedback Systems for Elite Sports Training. IEEE Pervasive Computing 5, 4 (2006), 70-76

2. Boehner, K. et al. How emotion is made and measured. International Journal of Human-Computer Studies 65, 4 (2007), 275-291.

3. Höök, K. Transferring qualities from horseback riding to design. NordiCHI 2010, (2010), ACM, 226-235.

4. Mueller, F. et al., Designing Sports: A Framework for Exertion Games. CHI '11, ACM, 2651-2660

5. Neustaedter, C. et al. Autobiographical Design: What You Can Learn From Designing for Yourself. Interactions 6, 2012, 28-33.

6. Schön, D.A. The Reflective Practitioner: How Professionals Think in Action. Basic Books, 1983.

7. Seifert, T. and Hedderson, C. Intrinsic Motivation and Flow in Skateboarding: An Ethnographic Study. Journal of Happiness Studies 11, 3 (2009), 277-292.

8. Sheridan, J. et al. Designing for Performative Tangible Interaction. International Journal of Arts and Technology 1, 3/4 (2008), 288-308.

9. Skate Sonic. http://www.otoplasma.com/skatesonic

10. Tron Ramp. https://vimeo.com/18525296.

11. Tholander, J. and Johansson, C. Design qualities for Whole Body Interaction - Learning from Golf , Skateboarding and BodyBugging. NordiCHI 2010, (2010), ACM, 493-502 